\title{
Study of the dependencies between more important pomological indicators in Cornel-Tree genotypes
}

\author{
Argir Zhivondov ${ }^{1}$, Neli Keranova ${ }^{2}$, Svetla Pandova ${ }^{1}$ \\ ${ }^{1}$ Department of Breeding and Genetic Resources, Fruit Growing Institute-Plovdiv, Ostromila, 12, 4000, Bulgaria, \\ a.zbivondov@abv.bg; cler66@abv.bg \\ ${ }^{2}$ Faculty of Economics, Department of Mathematics and Informatics, Agricultural University-Plovdiv, Mendeleev, 12, 4000, \\ Bulgaria; nelikeranova@abv.bg \\ Correspondingauthor:nelikeranova@abv.bg
}

Keywords: Cornus mas L., correlation coefficient, pomological indicators

Publication date 31/10/2019, http://www.m.elewa.org/JAPS

\section{$1 \quad$ ABSTRACT}

The object of this study is nine genotypes of Cornus mas L.: Kazanlashki pear-shaped, Pancharevski cylindrical, Shumenski oblong, Yaltenski, Vratsa-Castel Sandryan, Atkov cornel-tree, Tsarigradski yellow and Yellow Hadjiiski, distributed in the territory of Bulgaria. The objective of the study is the analysis of the impacts between more important pomological indicators and their presentation through linear models. The impacts between weight, length and width of the fruit, length of the stem, weight, length and width of the stone more important pomological indicators were researched by applying correlation analysis. The proven dependencies were evaluated and modelled by linear regression models presenting the complex effect of the tested signs on the weight of the fruit. The length of the fruit $(0.907)$, its width $(0.746)$, and the length of the stem $(0.605)$, the stone weight $(0.755)$, its length $(0.787)$ and its width $(0.605)$ had positive effect on fruit weight. After a regression equation was worked out, it was found that $90 \%$ of the dispersion of the dependent variable could be explained by the alteration of the irrigation, soil cultivation, pruning, which are not the subject of this study.

\section{INTRODUCTION}

Cornel-tree (Cornus mas L.) is a plant that is spread in Eastern and Southern Europe, the Caucasus, Southwest Asia. There is evidence of its existence since ancient times in Greece. In Bulgaria, it is most common in premountainous territories. It is well-known for its curative qualities and is therefore used both in folk medicine and in pharmacology. Widespread use and application of cornel-tree determine the interest of scientists in this field. There are a number of studies related to determining the interaction between quercetin and kaempferol (Pawlowska et al., 2010) and morphological indicators (Savikin et al., 2009;
Hassanpour et al., 2013; Mratinic et al., 2015). All of them are based on the usage of mathematical and statistical methods. The correlation and regression analyses are classic in this respect. Keatley and Hudson (2007) examined the change in the date of flowering of 65 genotypes of cornel-tree, spread in Australia. They found that 13 of them were affected by climate change. They believe that climate change is likely to affect the reproductive characteristics of plants. The proven dependencies are presented by regression equations. Yilmaz et al. (2009) examined the weight of cornel-tree fruits, its antioxidant 
characteristics and chemical indicators (ascorbic acid, common phenols, sugar, acids). They demonstrated the existence of linear relationships between antioxidant activity and the amount of total phenols. Kostekka et al. (2017) studied the content of vitamin C in fourteen newly-selected cornel-tree genotypes, the fruits of which are harvested at the end of August and September. They found that the new hybrids were significantly different from those existing so far in terms of vitamin C levels. They examined the dry substance in the relevant samples and identified a number of dependencies that they modelled through linear regression models. No statistically proven correlations have been obtained between dry matter content, fruit weight and vitamin C content. Taktak and Ilbay (2016) extrapolated polyphenols from cornel-tree leaves and proved that the $\mathrm{pH}$ content is the most important factor affecting this chemical indicator. The highest absorption rate is obtained at a $\mathrm{pH}$ value equal to 10 . Hassanpour and Ali Shiri (2014) studied the cornel-tree reproduction by analysing indicators related to its root system: percentage of rooted cuttings per genotype,

\section{METHODOLOGY}

The object of study nine genotypes of the cornel-tree: Kazanlashki pear-shaped, Pancharevski cylindrical, Shumenski oblong, Yaltenski, Vratsa-Castel Sandryan, Atkov cornel-tree, Tsarigradski yellow and Yellow Hadjiiski. The database is a result of the experimental work of a scientific team from the Plovdiv Institute of Fruit Growing for the period 2014-2017, as well as numerous literary sources in this field in Bulgaria and abroad; Klimenko, 2013 Kravchuk, 2003, Leontyk, 1984; Mezhenski, 2005; Tsolov, 1983; Zhivondov, et. al., 2007. The analysed pomological indicators were: weight, length and width of the fruit, length of the stem, weight, length and width of the stone. A correlation analysis was applied to determine the direction and degree of impact between the abovementioned signs. Pearson-Brave correlation coefficients were calculated. To avoid the root weight, root length. They modelled the proven dependencies by a square function, which is as close as possible to the experimental data. The highest percentage of rooted plants is found in genotype $\mathrm{C} 3$, which makes it preferred for future activities in the field of reproduction. There are no proven differences between soil types for rooting. Alijanpour (2017) made a quantitative and economical assessment of cornel-tree genotype for a three-year period. $\mathrm{He}$ considered the alteration in the height of the plant, the height of the crown, the crown diameter, the number of shoots, the annual fruit production. In order to determine the dependence between the vegetative characteristics and the quantity of fruits produced, a multiple regression analysis was applied. It was found that for the period 20122014 the total production volume was 17500 $\mathrm{kg}, 10705 \mathrm{~kg}$ and $8169 \mathrm{~kg}$ respectively. The present study makes a quantitative assessment of the nature and extent of the impact of various important pomological indicators in cornel-tree by applying correlation and regression analyses.

impact of the different dimensions of the indicators, the data were previously standardized. The regression analysis as a natural extension of the correlation analysis and serves to model the already established dependencies between individual indicators and their presentation in analytical form. The regression analysis as a set of statistical procedures is applied to examine the relations between one or several independent variables that are denoted by $x_{i}$ and (most often) a dependent variable that is denoted by $y$ (Ganeva, 2016). The purpose of linear regression analysis is to indicate the degree of linear dependence between two or more variables by calculating the regression constant and regression coefficients. The result of the regression analysis is an equation representing the best prognosis for the dependent variable as a function of the independent variables. The 
prognosis, figuratively speaking, is the process of assessing the values of the dependent variable based on previously known values of the independent variables, using the correlation concept.

\section{RESULTS AND DISCUSSION}

The correlation analysis proved the positive effect of the length of the fruit (0.907), its width (0.746), the length of the stem (0.605), the stone weight (0.755), its length (0.787) and width $(0.605)$ (Table 1$)$. The length of the fruit was positively influenced by its width $(0,695)$, the length of the stem (0.714), the weight (0.753), the length (0.855) and the width of the
For the mathematical processing of the experimental data, the statistical programme product IBM Statistics SPSS 24 (Cronk, 2012; Field, 2013; Garvanova, 2014; Weinberg and Abramowitz, 2016) was applied.

stone (0.465). The width of the fruit is moderately dependent on the weight $(0.418)$ and the width of the stone (0.363). There was a proved positive effect of stone size (respectively 0,787 and 0.542 ) on its weight, as well as the relationship between its width and its length (0.583). 
Table 1. Correlation coefficients presenting the dependencies between the pomological indicators in cornel-tree genotypes

\begin{tabular}{|c|c|c|c|c|c|c|c|}
\hline & $\begin{array}{l}\text { Weight of } \\
\text { the fruit (g) }\end{array}$ & $\begin{array}{l}\text { Length of } \\
\text { the fruit } \\
(\mathrm{mm})\end{array}$ & $\begin{array}{l}\text { Width of } \\
\text { the fruit } \\
(\mathrm{mm})\end{array}$ & $\begin{array}{l}\text { Length of } \\
\text { the stem } \\
(\mathrm{mm})\end{array}$ & $\begin{array}{l}\text { Weight of } \\
\text { the stone } \\
\text { (g) }\end{array}$ & $\begin{array}{l}\text { Length of } \\
\text { the stone } \\
(\mathrm{mm})\end{array}$ & $\begin{array}{l}\text { Width of } \\
\text { the stone } \\
(\mathrm{mm})\end{array}$ \\
\hline Weight of the fruit (g) & 1 & $0.907 * *$ & $0.746^{* *}$ & $0.605^{* *}$ & $0.755^{* *}$ & $0.787 * *$ & $0.605^{* *}$ \\
\hline Width of the fruit (mm) & & & 1 & 0.229 & $0.418^{*}$ & 0.316 & $0.363^{*}$ \\
\hline Length of the stem (mm) & & & & 1 & $0.820^{* *}$ & $0.834 * *$ & $0.501 * *$ \\
\hline Weight of the stone $(\mathrm{g})$ & & & & & 1 & $0.787 * *$ & $0.542^{* *}$ \\
\hline
\end{tabular}

**. Correlation is significant at the 0.01 level (2-tailed).

*. Correlation is significant at the 0.05 level (2-tailed)

Table 2. Regression coefficients, standard error, t-test, F-test and degrees of significance of the regression model, showing the effect of the length and weight of the fruit, the stem and the stone pomodological on the fruit weight in cornel-tree genotypes at a level of significance equal to 0.05

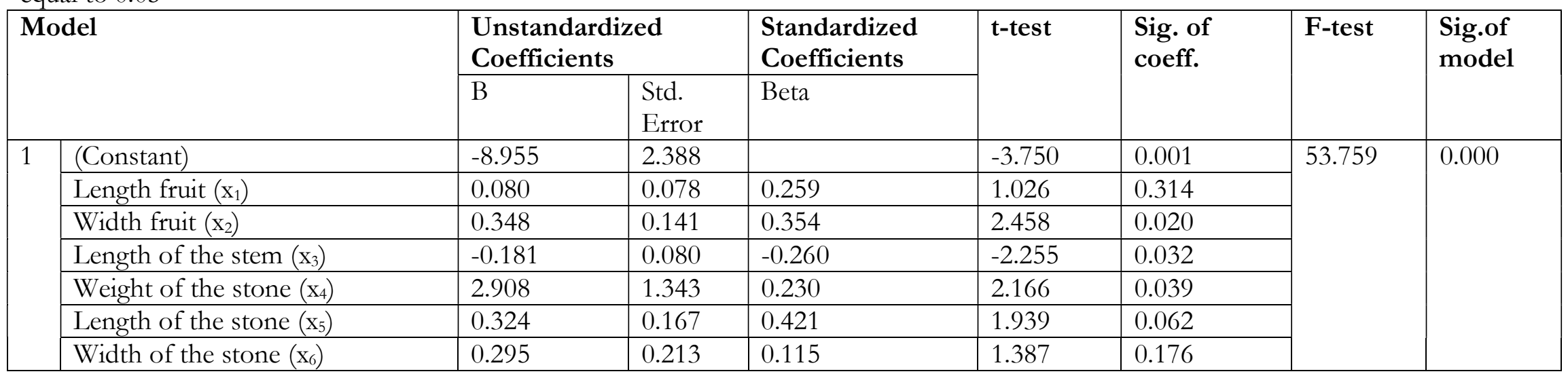


The complex effect of the six studied indicators on the fruit weight determines the application of multiple linear regression. The normal distribution of the dependent variable "fruit weight "was established beforehand, allowing regression analysis to be applied. As a result of this approach a model is compiled, presenting the proven correlation dependencies in analytical form:

$\mathrm{y}=-8.955+0.08 \mathrm{x}_{1}+0.348 \mathrm{x}_{2}-$

$0.181 \mathrm{x}_{3}+2.908 \mathrm{x}_{4}+0.324 \mathrm{x}_{5}+0.295 \mathrm{x}_{6}$,

Where $\mathrm{x}_{\mathrm{i}}(\mathrm{i}=1, \ldots, 6)$ denote the corresponding pomological indicators given in Table 2. From the information in this table it is clear that the compiled regression model is statistically significant. Considering the values of coefficients $\beta$, it can be stated that the stone length $(\beta=0.421)$ has the strongest positive effect on the weight of the fruit. It was found that $90 \%$ of the fruit weight dispersion can be explained by the change in the traits (due to the value of the Adjusted R Square). The remaining $10 \%$ of the variation is due to agro-technical measures for tree cultivation - irrigation, soil cultivation, pruning, which are not the subject of this study. Figures 1-6 illustrate the individual influence of each of the pomological indicators on the fruit weight. The graphs present both the regression models presenting the dependence between the respective signs and the coefficients of determination. The latter gives information about how much of the change in the fruit weight can be explained by the change of the corresponding independent variable. The graphical interpretation of regression dependencies gives reason to believe that the weight of the fruit is the biggest when its length is about $35 \mathrm{~mm}$ and the width is in the range $22-23 \mathrm{~mm}$. From the graphs in Figures 3-6 it follows that the maximum weight of the fruit is not achieved at the maximum values of the relevant indicators. The fruit is the heaviest $(9.74 \mathrm{~g})$ when the stone weight is about $0.57 \mathrm{~g}$, the stone length - about $17 \mathrm{~mm}$ and the width - approximately $8 \mathrm{~mm}$.

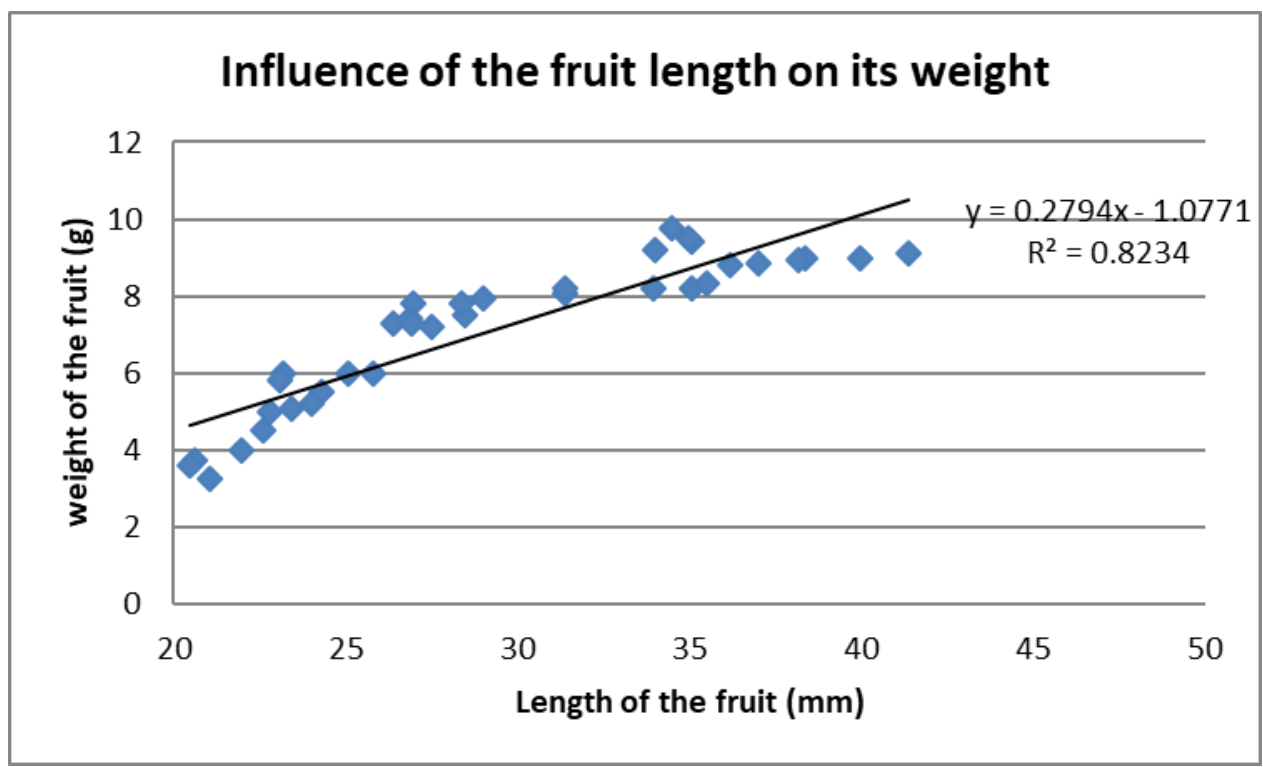

Figure 1: Graphic presentation of the influence of the length of the fruit on its weight 


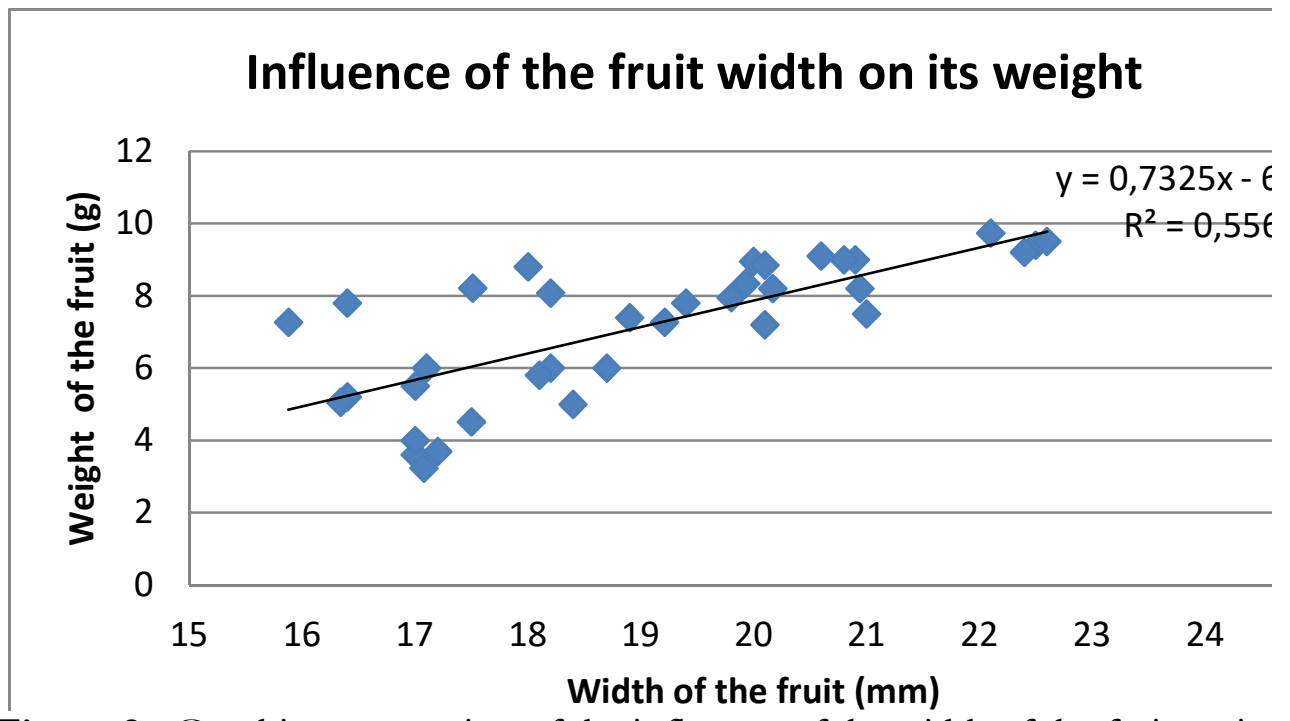

Figure 2: Graphic presentation of the influence of the width of the fruit on its weight

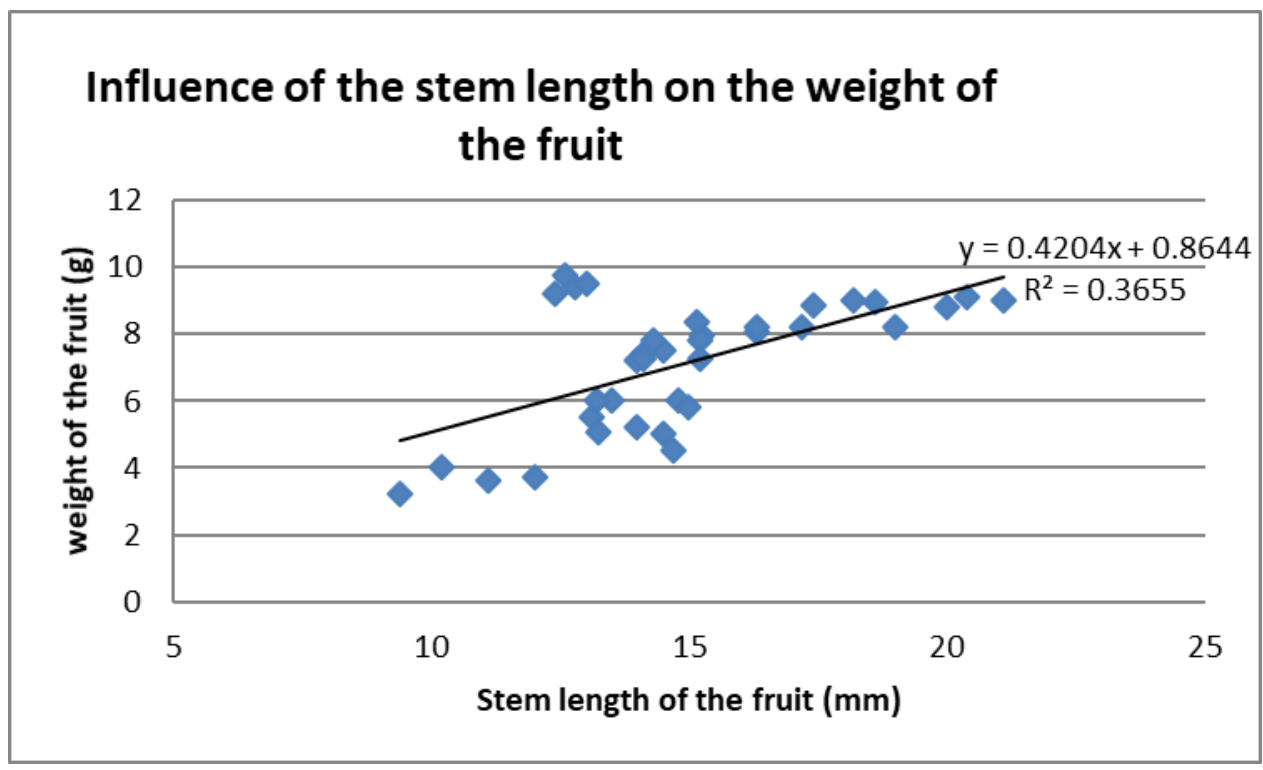

Figure 3: Graphic presentation of the influence of the stem of the fruit on fruit weight 


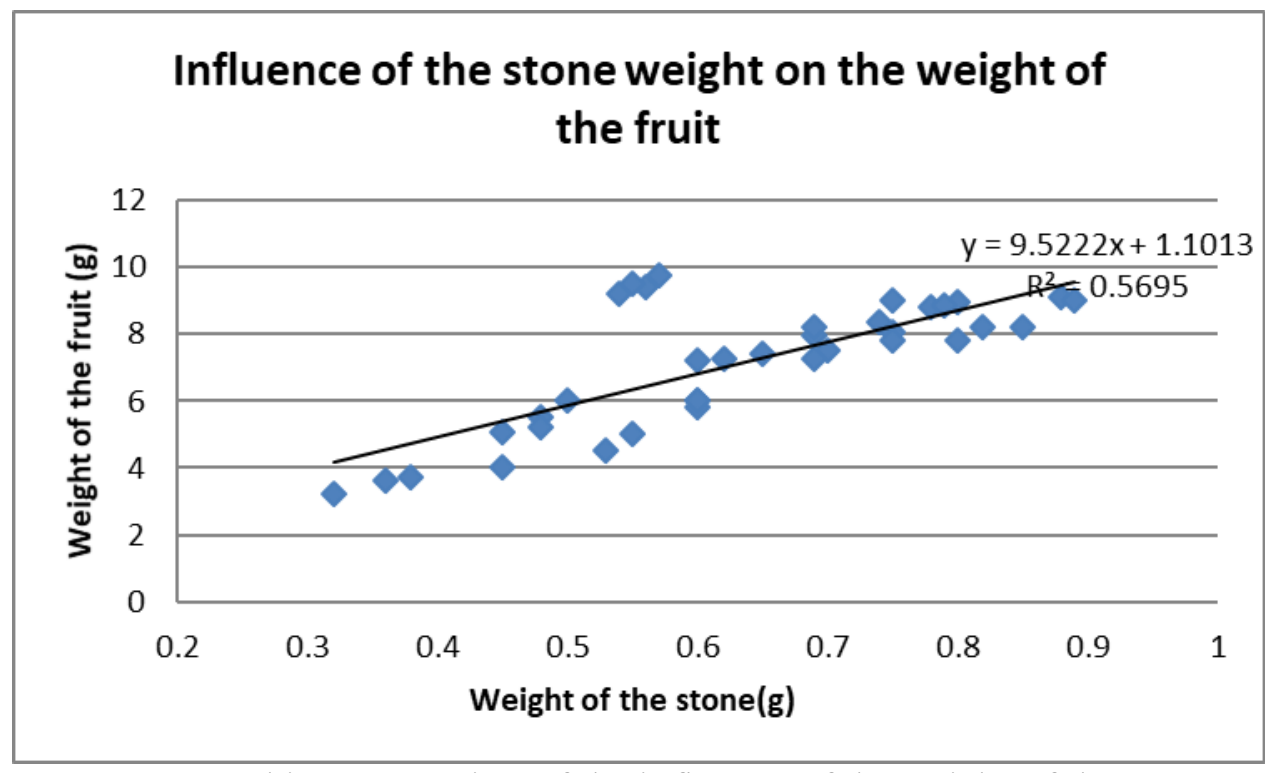

Figure 4: Graphic presentation of the influence of the weight of the stone on fruit weight

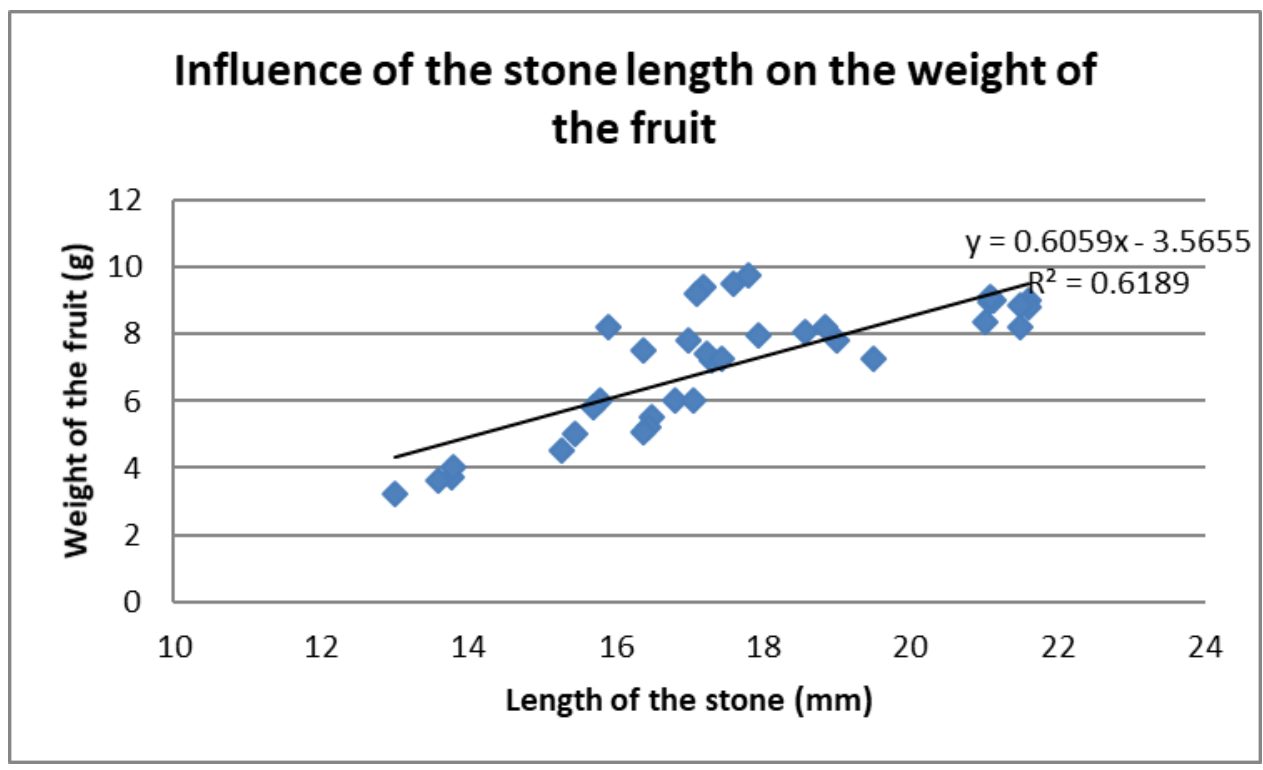

Figure 5. Graphic presentation of the influence of the length of the stone on fruit weight 


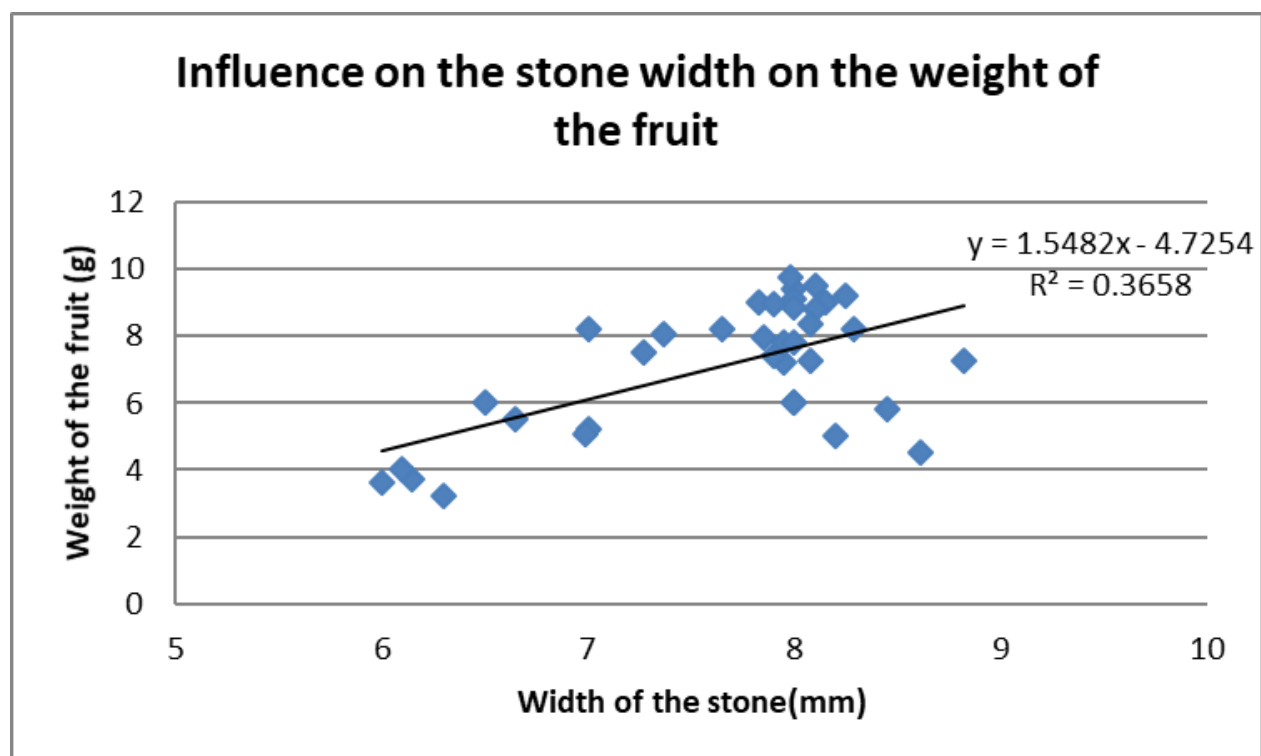

Figure 6. Graphic presentation of the influence of the stone width on the fruit weight

\section{CONCLUSION}

The conducted analyses proved the positive influence of all the pomological indicators included in the study on the fruit weight in cornel-tree genotypes, distributed on the territory of Bulgaria. After applying multiple linear regression, it was found that examining the complex influence of the signs on the fruit weight, the length of the stone has the strongest positive effect, followed by the width of the

\section{REFERENCES}

Alijanpour A: 2017. Cornelian cherry (Cornus mas L.) fruit as a non-timber forest product of Arasbaran biosphere reserve forests in Northwest of Iran, Forestry studies, 67: 72-85

Cronk B: 2012. How to use SPSS. A step-bystep guide to analysis and interpretation

Field A: 2013. Discovering Statistics using IBM SPSS Statistics, Mobile Study, London

Ganeva Z: 2016. To rediscover the statistics with SPSS, Elestra, Sofia, Bulgaria (In Bulgarian)

Hassanpour H, Hamidoghli $\mathrm{Y}$ and Samizadeh H: 2013. Estimation of genetic diversity in some Iranian cornelian cherries (Cornus mas L.) accessions using ISSR fruit. Studying the individual influence of each of the indicators on the fruit weight, it was proven that maximum weight was not achieved at the maximum values of each of the signs. The results of these analyses could be applied in future selection activities in order to increase the qualities of the newly-selected cornel-tree genotypes.

markers, Biochemical systematics and ecology, 48, 257-262

Hassanpour H and Ali Shiri M: 2014. Propagation of Iranian Cornelian cherry (Cornus mas L.) by rooted stem cuttings, Notulae scienia biologicae, 6 (2), $192-$ 195

Keatley M and Hudson I: 2007. Citeseer, Shift in flowering dates of Australian plants related to climate: $983-2006,504-510$

http://citeseerx.ist.psu.edu/viewdoc/download ?doi=10.1.1.566.1791\&rep= rep1\&type $=$ pdf

Klimenko C: 2013. Kizil - katalogov sortov, Interservis, Kiev, 3 - 5, 62 - 66 (In Russian) 
Kostecka M, Szot I, Czerneck T and Szot P: 2017. Vitamin C content of new ecotypes of Cornelian cherry (Cornus mas L.) determined by $\mathrm{v} \backslash$ rious analytical methods, Acta Sci. Pol. Hortorum Cultus, 16 (4), 53-61

Kravtchuk M: 2003. Agrobioligitcheski osobenosti perspectivni kulturi form kizila $\mathrm{v}$ pribukanskom zone sadovodstva, Avtorefferat dissertation, $3-22$ (in Russian)

Leontjak G: 1984. Kizil - cennoe lesnoe rastenie, Kischinev, Stiitca, 8 - 117 (In Russian)

Megenskij V: 2005. Kizil, Stalker, Doneck, Ukraina, 5 - 59 (In Russian)

Mratinic E, Aksic M, Rakonjac V, Miletic R and Zikic M: 2015. Morphological diversity of cornelian cherry (Cornus mas L.) populations in the Stara Planina Mountain, Serbia, Plant systematics and evolution, 301 (1), 365-374

Pawlowska A, Camangi F and Braca A: 2010. Quali-quantitative analysis of flavonoids of Cornus mas L. (Cornaceae) fruits, Food chemistry, 119 (3), 1257-1261

Savikin K, Zdunic G, Jankocic T, Stanojkovic T, Juranic Z and Menkovic N: 2009. In vitro cytotoxic and antioxidative activity of Cornus mas and Cotinus coggygria, Natural product research, 23 (18), 17311739

Taktak F and Ilbay Z: 2016. Novel polymerbentonite sorbent for recovery of antioxidant polyphenols from Cornus mas L. throughi process extraction/adsorption: optimization of extraction parameters by response surface methodology, Polymer-plastics technology and engineering, 55 (13), 1332-1343

Tcolov T: 1983. Edroploden drjan, Hristo Danov, Plovdiv, 9 - 107 (In Bulgarian)

Weinberg, S., Abramowitz, S. 2016. Statistics using IBM SPSS, An Integrative Approach, Cambridge University Press

Yilma, K, Ercisli S, Zengin Y, Sengul M and Kafkas E: 2009. Preliminary characterisation of cornelian cherry (Cornusmas L.) genotypes for their physico-chemical properties, Food chemistry, 114 (2), 408-412

Zhivondov A, Avanzato D and Tzareva I: 2007. Caratterizzazione carpologica e biochimica di selezioni di corniolo (Cornus mas L.) reperite in Bulgaria. Frutticoltura, 6, 50 - 52. 